\title{
Evaluation of iron bioavailability in a mixture of cereals, seeds, and grains ("Human Ration")
}

\author{
Bárbara Nery ENES ${ }^{1}$, Natália Elizabeth Galdino ALVES ${ }^{1}$, Samanta Thomas VALDÉS², \\ Carlos Mário Martins SILVEIRA ${ }^{1}$, Neuza Maria Brunoro COSTA³ ${ }^{3}$, Sônia Machado Rocha RIBEIRO ${ }^{1}$, \\ Shaila Turbay PIRES ${ }^{4}$, Hércia Stampini Duarte MARTINO ${ }^{1 *}$
}

\begin{abstract}
Iron bioavailability was evaluated in three mixtures of cereals, seeds, and grains ("Human Ration"): light, regular, and homemade provided to rats. The animals received an iron depletion diet for 21 days, followed by a repletion diet containing $12 \mathrm{mg} \cdot \mathrm{kg}^{-1}$ of iron for 14 days. The hemoglobin regeneration efficiency and the relative biological value did not differ between the light mixture and control group. The iron bioavailability of the light mixture of cereals, seeds, and grains and the control group were $99.99 \pm 27.62$ and $80.02 \pm 36.63$, respectively, while the regular and homemade mixtures of cereals, seeds, and grains showed lower iron bioavailability, $50.12 \pm 35.53$ and $66.66 \pm 15.44$, respectively; the iron content of the diet with light cereal mixture light was statistically similar to that of the control (ferrous sulfate $99.99 \pm 27.62)$. The high content of tannin $\left(202.81 \pm 19.53 \mathrm{mg} \cdot 100^{-1}\right)$ in the diet with the regular cereal mixture may have contributed to its low iron bioavailability. The higher intake of soluble fiber by the animals fed the light mixture $(21.15 \pm 0.92 \mathrm{~g})$ was moderately correlated $(\mathrm{r}=0.5712, p=0.0018)$ with the concentration of propionate in the caecal bulk $(65.49 \pm 11.08 \mu \mathrm{mol} / \mathrm{g})$. The short chain fatty acids produced by soluble fiber fermentation, associated with the low-content of tannin may have improved iron solubility and absorption in the light cereal mixture diet. The iron bioavailability in the light mixture of cereals, seeds, and grains was similar to that of ferrous sulfate.
\end{abstract}

Keywords: dietary fiber; minerals; bioavailability; short chain fatty acids; condensed tannin.

\section{Introduction}

Overweight and obesity are considered public health problems worldwide and have been a growing concern especially in urban areas of middle or low income countries (World Health Organization, 2011). Foods rich in dietary fiber have been used as a strategy to modulate body weight and reduce the risk of chronic diseases such as diabetes, dyslipidemia and obesity, due to their inherent physiological and physical properties (Mello \& Laaksonen, 2009). The intake of high-fiber foods is associated with lower food intake and therefore lower calorie intake (Slavin, 2005), which justifies the use of dietary fiber supplements in an attempt to lose weight.

However, the intake of foods rich in dietary fiber, mainly the insoluble fraction, is associated with decreased mineral absorption, especially divalent minerals (Shah et al., 2009). Commonly, these losses are not caused by fiber, but by other food matrix components such as phytates and tannins (Callegaro et al., 2010). The fiber-phytate-mineral relationship is complex and studies have attributed depressor effects to phytate on mineral absorption, including iron as the essential element most affected by phytate. Nevertheless, phytate fermentation in certain foods is able to reduce this adverse effect on bioavailability of minerals, and the same effect is observed for tannins (Towo et al., 2006; Schlemmer et al., 2009; Verma \& Banerjee, 2010).
Despite the high phytochemical content present in these plant foods, which can negatively affect mineral homeostasis, these dietary sources also contain a considerable amount of soluble dietary fiber. Fermentation of this fiber in the large intestine results in the production of short chain fatty acids (SCFA) that are used as energy source by colonocytes, as well as the reduction of luminal $\mathrm{pH}$ which may enhance minerals solubility and absorption (Scholz-Ahrens \& Schrezenmeir, 2007; Lobo et al., 2011).

Recent studies have shown an association between obesity and iron deficiency with elevated serum ferritin levels, even in the presence of true iron deficiency (Mcclung \& Karl, 2009; Neymotin \& Sen, 2011). This association agrees with literature findings, but the mechanisms have not yet been fully elucidated. The most accepted hypothesis is that the state of subclinical inflammation triggered by obesity increases the release of proinflammatory cytokines such as interleukin-6 (IL-6) and tumor necrosis factor- $\alpha$ (TNF- $\alpha$ ) that can induce the rise of hepcidin levels due to an increased release of this hormone by the liver and adipose tissue. This change may cause a decrease in the serum iron due to the binding of hepcidin to ferroportin 1 - a protein that aids the transport of iron through the basolateral membrane of the enterocyte into the bloodstream causing its internalization and degradation - thus reducing absorption of

${ }^{1}$ Departamento de Nutrição e Saúde, Universidade Federal de Viçosa - UFV, Viçosa, MG, Brasil, e-mail: hercia@ufv.br hercia@ufv.br

2 Universidade Federal de Santa Catarina - UFSC, Florianópolis, SC, Brasil

3 Centro de Ciências Agrárias, Universidade Federal do Espírito Santo - UFES, Alegre, ES, Brasil

${ }^{4}$ Universidade Federal do Vale do Jequitinhonha e Mucuri - UFVJM, Diamantina, MG, Brasil

${ }^{*}$ Corresponding author 
the mineral. Elevated levels of serum ferritin may be explained by the elevated levels of iron within the enterocytes (Bekri et al., 2006; Zimmermann \& Hurrell, 2007).

In Brazil, foods referred as "natural and functional foods" have gained considerable importance in the food market. Accordingly, a commercial product called "Human Ration", a mixture of cereals, seeds, and grains (MC) has been commercialized. It consists of several ingredients which, individually, have chemical compounds and characteristics that can produce positive physiological effects on human health, such as flaxseed, oat bran, wheat germ and fiber, and defatted soy flour, among others. However, there is no scientific evidence that a combination of these ingredients would have beneficial and/or potential adverse effects on human health and iron bioavailability.

"Human Ration" stands out among other fiber supplements used to control weight; however, there are risk factors related to the maintenance of iron homeostasis. Therefore, the present study aimed to evaluate the iron bioavailability of three mixtures of cereals, seeds, and grains ("Human Ration"): light, regular, and homemade provided to Wistar rats.

\section{Materials and methods}

The experimental protocol was approved by the Ethics Committee for Animal Research of the Federal University of Viçosa (45/2011), according to the guidelines of the Brazilian College on Animal Experimentation. The present study was conducted between March and July 2011, in Viçosa, Minas Gerais, Brazil.

\subsection{Iron deficiency protocol}

The assessment of iron bioavailability was based on the depletion/repletion method of the Association of Official Analytical Chemists (AOAC) at $12 \mathrm{mg} \cdot \mathrm{kg}^{-1}$. The biological assay was performed using 32 weaning male Wistar rats (Rattus norvegicus, albinus variety, and class Rodentia) obtained from the Animal Center Health Sciences of the Federal University of Viçosa, Minas Gerais, Brazil. The animals were distributed into individual stainless steel cages under controlled temperatures $\left(22 \pm 3{ }^{\circ} \mathrm{C}\right)$ and relative humidity $(55 \pm 10 \%)$ with a 12-h lightdark cycle (lights on from 07.00 to $19.00 \mathrm{~h}$ ).

In the depletion period, all animals received deionized water ad libitum and were fed an AIN-93 G (Reeves et al., 1993) iron deficient diet (Table 1) to induce iron deficiency for 21 days. At the end of the depletion period, blood samples from the tail were obtained, and Hemoglobin $(\mathrm{Hb})$ concentration was assessed via the cyanide $\mathrm{Hb}$ method (Drabkin \& Austin, 1935) (Bioclin, Belo Horizonte, Minas Gerais, Brazil).

\subsection{Hemoglobin regeneration assay}

The animals were divided into four experimental groups based on the value of body weight $(\mathrm{g}) \mathrm{x} \mathrm{Hb}$ concentration $\left(\mathrm{g} \cdot \mathrm{dL}^{-1}\right)$ and were fed a modified AIN-93G diet containing $12 \mathrm{mg} \cdot \mathrm{kg}^{-1}$ of $\mathrm{Fe}$ however, the Fe source of the control group diet was ferrous sulfate $\left(\mathrm{FeSO}_{2}\right)$. The RMC (regular mixture of cereals, seeds, and grains), LMC (light mixture of cereals, seeds, and grains), and HMC (homemade mixture of cereal, seeds, and grains) diets provided the same concentration of iron $\left(12 \mathrm{mg} \cdot \mathrm{kg}^{-1}\right)$ and were also based on AIN-93 composition. The other components of these diets were manipulated to match

Table 1. Experimental diets' constituents $\left(\mathrm{g} \cdot \mathrm{kg}^{-1}\right)$ and iron and tannin content $\left(\mathrm{mg} \cdot \mathrm{kg}^{-1}\right)$.

\begin{tabular}{|c|c|c|c|c|c|}
\hline \multirow{2}{*}{ Constituents } & \multirow{2}{*}{ Depletion diet } & \multicolumn{4}{|c|}{ Repletion diets } \\
\hline & & CG Diet & HMC Diet & RMC Diet & LMC Diet \\
\hline Albumin $^{\mathrm{a}}$ & 200.00 & 200.00 & 147.28 & 183.38 & 172.59 \\
\hline Maltodextrin $^{\mathrm{a}}$ & 132.00 & 132.00 & 132.00 & 132.00 & 132.00 \\
\hline Sucrose $e^{b}$ & 100.00 & 100.00 & 100.00 & 100.00 & 100.00 \\
\hline Soybean oil ${ }^{c}$ & 70.00 & 70.00 & 44.53 & 62.25 & 50.30 \\
\hline Fiber $^{\mathrm{d}}$ & - & - & 20.17 & 37.41 & 21.26 \\
\hline Cellulose Microfine $e^{e}$ & 50.00 & 50.00 & 29.83 & 12.59 & 28.74 \\
\hline Iron free mineral mixture ${ }^{f}$ & 35.00 & 35.00 & 35.00 & 35.00 & 35.00 \\
\hline Vitamin mixture ${ }^{g}$ & 10.00 & 10.00 & 10.00 & 10.00 & 10.00 \\
\hline L-Cystine ${ }^{g}$ & 3.00 & 3.00 & 3.00 & 3.00 & 3.00 \\
\hline Choline Bitartrate ${ }^{g}$ & 2.50 & 2.50 & 2.50 & 2.50 & 2.50 \\
\hline Corn starch ${ }^{\mathrm{h}}$ & 397.50 & 397.50 & 315.43 & 362.98 & 352.09 \\
\hline Ferrous sulphate $\mathrm{e}^{\mathrm{i}}$ & - & 0.06 & - & - & - \\
\hline HMC & - & - & 190.06 & - & - \\
\hline $\mathrm{RMC}$ & - & - & - & 157.22 & - \\
\hline LMC & - & - & - & - & 121.24 \\
\hline Iron ${ }^{* *}$ & - & $1.73 \pm 0.04$ & $1.93 \pm 0.9$ & $2.32 \pm 0.01$ & $2.54 \pm 0.07$ \\
\hline Tannin ${ }^{* *}$ & - & - & $59.76 \pm 7.28$ & $202.81 \pm 19.53$ & $27.88 \pm 2.94$ \\
\hline
\end{tabular}

Source: Adapted from Reeves et al. (1993); except of iron. CG: Control group (ferrous sulfate); HMC: Homemade mixture of cereals, seeds, and grains; RMC: Regular mixture of cereals, seeds, and grains; LMC: light mixture of cereals, seeds, and grains. a Maxnutry Albumina 100\% pura/ Nutryclin Alimentos Viçosa Brazil. b Açúcar União/ Commerce of Viçosa. c SOYA/ Commerce of Viçosa. d Fiber from the mixture of cereals, seeds, and grains used to prepare the test diet. e Synth, LabSynth Produtos para Laboratório LTDA. f Laboratory of Experimental Nutrition-UFV-MG-Brazil. g Rhoster/ Rhoster-Indústria e Comércio Ltda. h Maizena Amido de Milho. i VETEC Química Fina LTDA. ** Content measured. 
the MC chemical composition concerning macronutrients and energy. The dietary intake was controlled to provide 16 to $18 \mathrm{~g}$ per day and was monitored weekly. The animals were fed these diets for a period of 14 days (repletion).

At the end of the repletion period, the animals were anaesthetized in $\mathrm{CO}_{2}$ atmosphere to induce unconsciousness and were then immediately euthanized by cardiac puncture. Blood samples were collected, and the caecum was removed, weighed, and cut open along the small curvature. Caecal $\mathrm{pH}$ was measured in situ by inserting an electrode (Schoott, Handylab 1, Germany) through the ileocaecal junction (Lobo et al., 2007). The fecal contents were stored at $-80^{\circ} \mathrm{C}$ for SCFA analysis.

\subsection{Formulation of experimental diets and chemical composition}

Three types of cereals, seeds, and grain mixture, regular (RMC), light (LMC), and homemade (HMC), were used. The regular formulation was obtained from a local market in Viçosa, MG, Brazil; the light formulation was kindly donated by the product manufacturer, and the homemade formulation was prepared in the laboratory following the proportions of ingredients in the original recipe. The RMC and HMC formulations consisted of quinoa, agar-agar, brown sugar, oatmeal, cocoa powder, oat bran, wheat fiber, rice flour, white cornmeal, flour, defatted soy, sesame, wheat germ, guarana powder, brewer's yeast, and flaxseed. The LMC formulation was composed of: quinoa, agar-agar, oatmeal, oat bran, passion fruit peel flour, wheat germ, rice flour, defatted soy flour, sesame, wheat germ, brewer's yeast, and flaxseed. The experimental diets (Table 1) were formulated according to the standard rodent diet AIN-93G. In the HMC, LMC, and RMC formulations, cornstarch, sucrose, and dietary fiber were quantitatively replaced, taking into consideration the carbohydrate content in the mixtures of cereals, seeds, and grains, and the diets were maintained isoproteic and isocaloric. After preparation, the diets were stored under refrigeration $\left(-20^{\circ} \mathrm{C}\right)$.

Moisture, ash, protein, lipids, starch, total dietary fiber, and fractions were determined according to the Association of Official Analytical Chemists (2002). The iron content in the samples was determined according to Gomes (1996), in which $1 \mathrm{~g}$ of the sample was digested in concentrated nitric acid at $150{ }^{\circ} \mathrm{C}$ for 16 hours until a clear solution was formed. The iron concentration in the solution was measured by atomic absorption spectrophotometry (GBC 908 AA spectrophotometer). Phytate determination was carried out by the colorimetric method according to Latta \& Eskin (1980). This was performed using a UV-Visible spectrophotometer (Shimadzu, UV-1601, Japan) at the wavelength of $500 \mathrm{~nm}$. Condensed tannins were determined by vanillin reaction according to Burns (1971) with modifications, as proposed by Maxson \& Rooney (1972) and Price et al. (1978).

\subsection{Iron bioavailability and hematological parameters}

Blood samples were collected by cardiac puncture and divided into two vials: without anticoagulant for $\mathrm{Hb}$ determination and with anticoagulant (EDTA, Vacuette, Campinas, Brazil) for reticulocytes counts.

Hemoglobin gain (HbG) was calculated as the difference in $\mathrm{Hb}$ concentration obtained in the final and initial phases of the repletion period.

$\mathrm{Hb}$-Fe pool was calculated, assuming the total blood volume of $6.7 \%$ body weight and hemoglobin iron of $0.335 \%$ (Equation 1):

Hb-Fe pool $(\mathrm{mg})=\left[\right.$ body weight $\left.(\mathrm{g}) \times \mathrm{Hb}\left(\mathrm{g} \mathrm{L}^{-1}\right) \times 6.7 \times 0.335\right] / 10,000$

$\mathrm{Hb}$ regeneration efficiency and relative biological value were estimated according to Mahoney et al. (1974) (Equations 2 and 3$)$ :

$\mathrm{Hb}$ regeneration efficiency (HRE):

$\% \mathrm{HRE}=m g \mathrm{Hb}-\mathrm{Fe}_{\text {final }}-\mathrm{mg} \mathrm{Hb}-\mathrm{Fe} e_{\text {initial }} / \mathrm{Fe}$ intake $(\mathrm{mg})$

Relative biological value (RBV):

$\mathrm{RBV}=100 \mathrm{X}(\mathrm{HRE}(\%)$ test group/HRE $(\%)$ control group

The amount of iron consumed (mg) was determined by the value of total dietary consumption ( $\mathrm{g}$ ) $\mathrm{x}$ Fe of the diet (mg). Apparent iron bioavailability of the experimental groups was assessed by comparing it with that of the control group, whose RBV was considered $100 \%$. Reticulocyte counts were carried out according to Zago et al. (2005).

\subsection{Determination of SCFA in the caecal contents}

The method described by Smiricky-Tjardes et al. (2003) was used in the caecal SCFA (acetate, propionate and butyrate) analysis. The SCFA concentrations were determined by High Performance Liquid Chromatography (HPLC) (Shimadzu Scientific Instruments Inc., Kyoto, Japan) equipped with a SPD10A VP pump and a Shimadzu $\mathrm{C}_{18}$ chromatography column $30 \mathrm{~cm} \times 4.5 \mathrm{~mm}$ and coupled to an Ultra Violet (UV) detector. The chromatographic conditions were: mobile phase composed of ultrapure water (Milli-Q) in 1\% ortho-phosphoric acid, $20 \mathrm{~mL}$ injection volume, flow rate of $1.0 \mathrm{~mL} / \mathrm{min}$, and pressure of $138 \mathrm{kgf}$. Chromatograms were obtained at $210 \mathrm{~nm}$.

Aliquots of caecal content (500 mg) were added to $500 \mu \mathrm{L}$ of $25 \%$ meta-phosphoric acid and left for $30 \mathrm{~min}$ at room temperature. Samples were then centrifuged in a refrigerated micro centrifuge (Hitachi, CT15RE, Koki, Japan) at 16,000 rpm and $5{ }^{\circ} \mathrm{C}$ for $30 \mathrm{~min}$. The supernatant was collected and centrifuged for $20 \mathrm{~min}$ under the same conditions. Identification of compounds was performed by comparison with the retention times of the standards (Volatine Free Acid Mix, code 46975; Sigma Chemical CO., St. Louis, MO, USA). The samples were analyzed under the same conditions as those of the standards, and quantification was performed using external standard curves constructed by injecting increasing concentrations of the standard solutions in duplicate at intervals ranging from 500 to $2500 \mathrm{ppm}, 2000$ to $8000 \mathrm{ppm}$, and 50 to $300 \mathrm{ppm}$ of acetic, propionic, and butyric acid, respectively. A linear correlation was defined between the peak areas and the injected concentrations of each fatty acid. 
Quantification of SCFA in the samples was performed using the analytical curves and regression equations for acetic acid $\left(\mathrm{y}=577.01 \mathrm{x}+10539 ; \mathrm{R}^{2}=0.997\right)$, propionic acid $\left(y=656.23 x-38691 ; R^{2}=0.9978\right)$, and butyric acid $\left(y=585.36 x+1651 ; R^{2}=0.9987\right)$. The concentrations of the samples were calculated by including the dilution factor.

\subsection{Statistical analysis}

Data was expressed as mean \pm standard deviation. In the depletion period, the values of hemoglobin concentration and $\mathrm{Hb}$ Fe pool from day 0 and 14 were compared using paired $t$-test. For comparison between the means of the different groups, analysis of variance (ANOVA) was performed and, in the case of significant differences, the Dunnett's post hoc test was applied using the ferrous sulfate group (Control) as standard. The Duncan's test was used to make comparisons between the experimental groups. Body weight, body weight gain, and food efficiency ratio were adjusted based on the food intake, while initial and final hemoglobin concentration, hemoglobin gain, and $\mathrm{Hb}-\mathrm{Fe}$ were corrected based on the iron intake. Data analysis was carried out using the software System for Statistical Analysis (SAEG) version 9.1, considering a significance level of $5 \%(p<0.05)$.

\section{Results}

\subsection{Chemical composition of the mixtures of cereals, seeds, and grains}

The chemical composition of the mixtures of cereals, seeds, and grains are shown in Table 2. The formulations were rich in protein and lipids, contributing to the average energy density of the products in $337.81 \mathrm{kcal} \cdot 100 \mathrm{~g}^{-1}$. The phytate: iron molar ratio of the HMC formulation (8.27) was significantly higher than that of the LMC formulation (3.44) and of the RMC formulation (1.64). The tannin content of the RMC formulation was higher than that of to the other diets, as shown in Table 1, while HMC and LMC formulations had similar concentrations.

\subsection{Body weight gain and food consumption}

A depletion period of 21 days was sufficient to produce iron deficiency in the animals. In the repletion period, all groups showed body weight gain similar to that of the control group (CG) after the adjustment of the total dietary intake. Among the experimental groups, except for the control group, the highest body weight gain was observed for the HMC group.

The highest FER value was observed for the HMC group, when compared with the control and the tested groups, which is justified by the increased food intake (Table 4).

\subsection{Hematological and iron bioavailability parameters}

There was no statistical difference in the $\mathrm{Hb}$ concentration $(P=0.09)$ and $\mathrm{Hb}-\mathrm{Fe}$ pool $(p=0.065)$ between the experimental groups at the end of the depletion period (Table 3 ). $\mathrm{Hb}$ values and $\mathrm{Hb}-\mathrm{Fe}$ pool between the beginning and the end of the repletion period are shown in Figure 1. The mean $\mathrm{Hb}$ concentration increased by $39.2 \%(p<0.0001)$ for the CG, $28.6 \%$ $(p=0.0001)$ for HMC, 36.5\% ( $p=0.0015)$ for LMC, and $27.2 \%$ $(P=0.0315)$ for RMC (Figure 1-A). Hb-Fe pool had similar results, with an increase of $47.7 \%$ for the CG $(p<0.0001), 38.8 \%$ for HMC ( $p<0.0001), 46.8 \%$ for LMC ( $p=0.0004)$, and $38.2 \%$ for RMC ( $p=0.0048$ ) (Figure 1-B). The relative biological value of the LMC (80.02\%) was similar to that of the GC (99.99\%) (Table 4). Mineral bioavailability showed no statistical difference between the three different mixtures $(p=0.2497)$. RMC showed the highest iron content $\left(17.52 \mathrm{mg} \cdot 100 \mathrm{~g}^{-1}\right)$, followed by LMC (12.42 mg.100 g $\mathrm{g}^{-1}$ ), and HMC (6.24 mg.100 g $\left.\mathrm{g}^{-1}\right)$ (Table 2). However, only $8.78 \mathrm{mg}, 9.93 \mathrm{mg}$, and $4.15 \mathrm{mg}$ of iron, respectively, were bioavailable.

Animals fed LMC had higher intake of total and soluble dietary fiber, and the RMC group had higher intake of insoluble dietary fiber (Table 5). In the present study, no association was found between iron bioavailability and dietary fiber intake and/ or fractions. The HMC and LMC groups had higher caecal propionate contents than those of the GC. With regard to

Table 2. Chemical composition ( $\left.\mathrm{g} \cdot 100 \mathrm{~g}^{-1}\right)$, iron, phytate, and tannin contents (mg. $\mathrm{g}^{-1}$ ) of Homemade (HMC), Regular (RMC), and Light (LMC) mixtures of cereals, seeds, and grains (dry basis).

\begin{tabular}{|c|c|c|c|}
\hline Composition & $\mathrm{HMC}$ & LMC & RMC \\
\hline Protein & $20.00 \pm 0.05^{\mathrm{a}}$ & $15.14 \pm 0.02^{c}$ & $17.08 \pm 0.08^{b}$ \\
\hline Fat & $13.40 \pm 0.33^{\mathrm{b}}$ & $16.25 \pm 0.84^{\mathrm{a}}$ & $10.85 \pm 0.31^{c}$ \\
\hline Starch & $39.37 \pm 1.28^{\mathrm{a}}$ & $31.75 \pm 0.59^{\mathrm{a}}$ & $38.90 \pm 2.89^{\mathrm{a}}$ \\
\hline Moisture & $6.93 \pm 0.00^{b}$ & $8.75 \pm 0.10^{\mathrm{a}}$ & $9.05 \pm 0.58^{\mathrm{a}}$ \\
\hline Ash & $3.88 \pm 0.00^{\mathrm{b}}$ & $4.47 \pm 0.02^{\mathrm{a}}$ & $4.41 \pm 0.07^{\mathrm{a}}$ \\
\hline Total Dietary Fiber & $16.40 \pm 1.00^{\mathrm{b}}$ & $23.65 \pm 0.07^{\mathrm{a}}$ & $20.29 \pm 3.80^{b}$ \\
\hline Insoluble Dietary Fiber & $13.68 \pm 0.57^{\mathrm{a}}$ & $14.62 \pm 0.07^{\mathrm{a}}$ & $14.89 \pm 4.44^{\mathrm{a}}$ \\
\hline Soluble Dietary Fiber & $2.72 \pm 0.42^{c}$ & $9.03 \pm 0.14^{\mathrm{a}}$ & $5.40 \pm 0.64^{\mathrm{b}}$ \\
\hline Iron & $6.24 \pm 0.00^{c}$ & $12.42 \pm 0.58^{\mathrm{b}}$ & $17.52 \pm 0.02^{\mathrm{a}}$ \\
\hline Phytate & $6.20 \pm 0.60^{\mathrm{a}}$ & $4.00 \pm 0.30^{\mathrm{b}}$ & $3.30 \pm 0.30^{c}$ \\
\hline Tannin & $2.78 \pm 0.38^{b}$ & $2.02 \pm 0.24^{b}$ & $12.45 \pm 1.24^{\mathrm{a}}$ \\
\hline Phytate: iron & $8.28 \pm 0.76^{\mathrm{a}}$ & $3.44 \pm 0.95^{\mathrm{b}}$ & $1.64 \pm 0.14^{\mathrm{c}}$ \\
\hline Energy density & $319.16 \pm 14.71^{\mathrm{a}}$ & $333.91 \pm 5.17^{\mathrm{a}}$ & $358.13 \pm 2.29^{a}$ \\
\hline
\end{tabular}

Results are expressed as mean \pm SD from three repetitions. For each evaluated characteristic, means followed by the same lowercase letter in the lines are not significantly different at $5 \%$ probability by Duncan test. HMC: Homemade mixture of cereals, seeds, and grains; LMC: Light mixture cereals, seeds, and grains; RMC: Regular mixture of cereals, seeds, and grains. 
Table 3. Body weight, body weight gain, diet consumption, food efficiency ratio, and hemoglobin concentration in the depletion period.

\begin{tabular}{ccccc}
\hline Variables & CG & HMC & LMC & RMC \\
\hline Initial body weight (g) & $81.37 \pm 15.3^{\mathrm{A}}$ & $90.87 \pm 7.64^{\mathrm{Aa}}$ & $89.62 \pm 8.39^{\mathrm{Aa}}$ & $86.37 \pm 8.97^{\mathrm{Aa}}$ \\
Final body weight (g) & $178.12 \pm 18.3^{\mathrm{A}}$ & $179.87 \pm 15.52^{\mathrm{Aa}}$ & $187.25 \pm 15.69^{\mathrm{Aa}}$ & $184.5 \pm 17.14^{\mathrm{Aa}}$ \\
Body weight gain (g) & $96.75 \pm 7.36^{\mathrm{A}}$ & $89.0 \pm 15.25^{\mathrm{Aa}}$ & $97.62 \pm 14.62^{\mathrm{Aa}}$ & $98.12 \pm 17.14^{\mathrm{Aa}}$ \\
Consumption (g) & $295.68 \pm 19.5^{\mathrm{A}}$ & $293.81 \pm 26.79^{\mathrm{Aa}}$ & $308.03 \pm 27.88^{\mathrm{Aa}}$ & $303.33 \pm 24.90^{\mathrm{Aa}}$ \\
Food Efficiency Ratio & $0.33 \pm 0.03^{\mathrm{A}}$ & $0.30 \pm 0.03^{\mathrm{Aa}}$ & $0.32 \pm 0.03^{\mathrm{Aa}}$ & $0.32 \pm 0.03^{\mathrm{Aa}}$ \\
Hemoglobin Concentration (g/dL) & $7.33 \pm 1.17^{\mathrm{A}}$ & $7.17 \pm 0.94^{\mathrm{Aa}}$ & $7.28 \pm 1.15^{\mathrm{Aa}}$ & $7.74 \pm 1.05^{\mathrm{Aa}}$ \\
\hline
\end{tabular}

Results are expressed as mean \pm SD. CG: Control group; HMC: Homemade mixture of cereals, seeds, and grains; LMC: Light mixture cereals, seeds, and grains; RMC: Regular mixture of cereals, seeds, and grains. For each evaluated characteristic, means followed by the same capital letter in the lines are not significantly different at $5 \%$ probability by Dunnett's test. For each evaluated characteristic, means followed by the same lowercase letter in the lines are not significantly different at $5 \%$ probability by Duncan's test.

Table 4. Body weight, food efficiency ratio, and hematological parameters of the experimental groups during the repletion period.

\begin{tabular}{ccccc}
\hline Variables & CG & HMC & LMC & RMC \\
\hline Initial body weight (g) & $189.27 \pm 18.38^{\mathrm{A}}$ & $174.08 \pm 15.52^{\mathrm{Aa}}$ & $181.32 \pm 15.69^{\mathrm{Aa}}$ & $185.08 \pm 17.30^{\mathrm{Aa}}$ \\
Final body weight (g) & $223.08 \pm 28.09^{\mathrm{A}}$ & $218.56 \pm 15.83^{\mathrm{Aa}}$ & $216.89 \pm 16.75^{\mathrm{Aa}}$ & $218.47 \pm 16.15^{\mathrm{Aa}}$ \\
Body weight gain (g) & $33.80 \pm 13.90^{\mathrm{A}}$ & $44.48 \pm 2.90^{\mathrm{Aa}}$ & $35.57 \pm 10.00^{\mathrm{Ab}}$ & $33.39 \pm 8.01^{\mathrm{Ab}}$ \\
Food Efficiency Ratio & $0.12 \pm 0.06^{\mathrm{B}}$ & $0.19 \pm 0.02^{\mathrm{Aa}}$ & $0.16 \pm 0.04^{\mathrm{Bb}}$ & $0.14 \pm 0.03^{\mathrm{Bb}}$ \\
Hemoglobin gain (g/dL) & $5.08 \pm 1.36^{\mathrm{A}}$ & $2.36 \pm 0.73^{\mathrm{Ba}}$ & $4.06 \pm 2.35^{\mathrm{Aa}}$ & $2.41 \pm 2.92^{\mathrm{Ba}}$ \\
Hemoglobin regeneration efficiency (\%) & $0.61 \pm 0.20^{\mathrm{A}}$ & $0.40 \pm 0.10^{\mathrm{Ba}}$ & $0.50 \pm 0.20^{\mathrm{Aa}}$ & $0.30 \pm 0.20^{\mathrm{Ba}}$ \\
Relative biological value & $9.99 \pm 2.76^{\mathrm{A}}$ & $6.66 \pm 1.54^{\mathrm{Ba}}$ & $8.00 \pm 3.56^{\mathrm{Aa}}$ & $5.01 \pm 3.55^{\mathrm{Ba}}$ \\
Iron bioavailability (\%) & $99.99 \pm 27.62^{\mathrm{A}}$ & $66.66 \pm 15.44^{\mathrm{Ba}}$ & $80.02 \pm 36.63^{\mathrm{Aa}}$ & $50.12 \pm 35.53^{\mathrm{Ba}}$ \\
Reticulocyte count (\%) & $97.50 \pm 31.11^{\mathrm{A}}$ & $82.80 \pm 19.76^{\mathrm{Aa}}$ & $112.50 \pm 12.80^{\mathrm{Aa}}$ & $90.00 \pm 39.76^{\mathrm{Aa}}$ \\
\hline
\end{tabular}

Results are expressed as mean \pm SD. CG: Control group; HMC: Homemade mixture of cereals, seeds, and grains; LMC: Light mixture cereals, seeds, and grains; RMC: Regular mixture of cereals, seeds, and grains. For each evaluated characteristic, means followed by the same capital letter in the lines are not significantly different at $5 \%$ probability by Dunnett's test. For each evaluated characteristic, means followed by the same lowercase letter in the lines are not significantly different at $5 \%$ probability by Duncan's test.
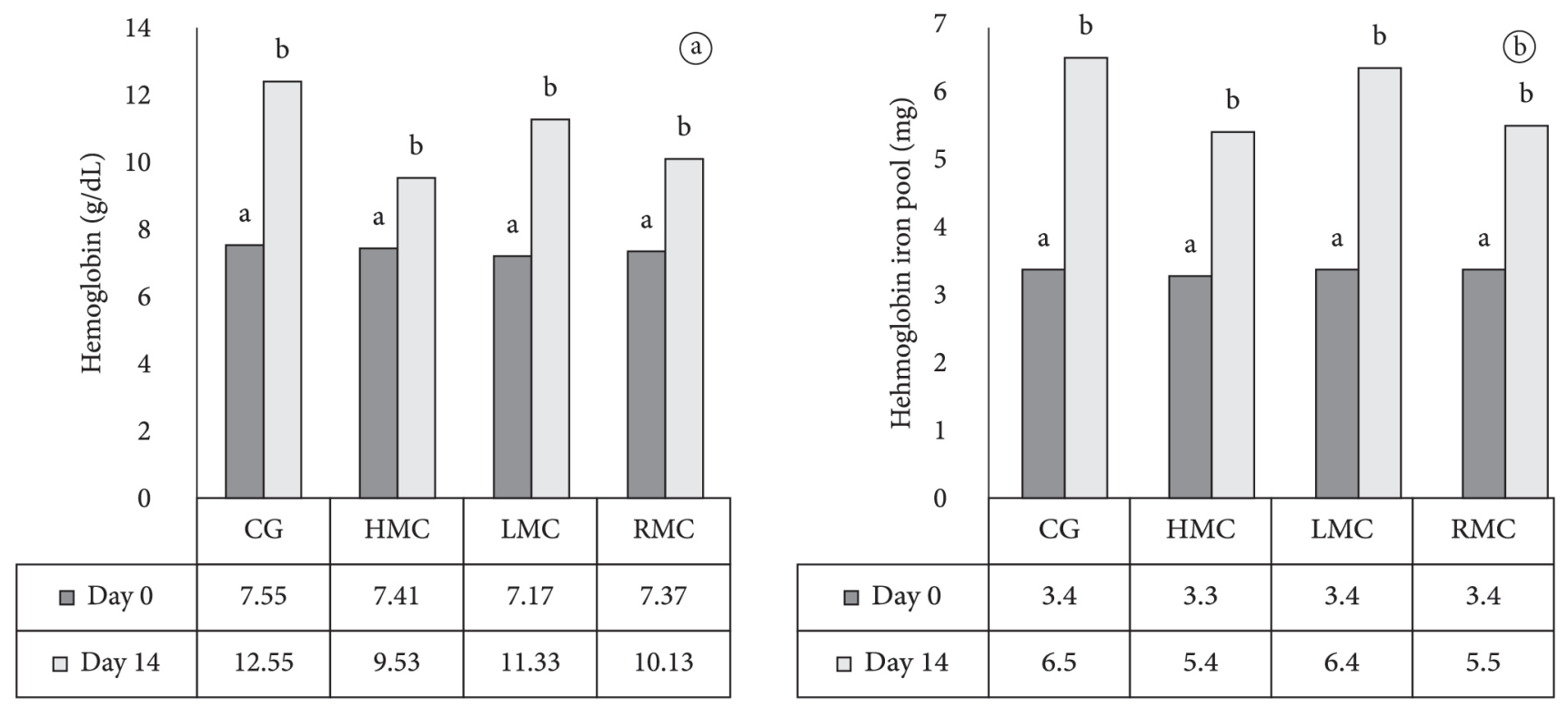

Figure 1. Hemoglobin concentration and Hemoglobin iron pool in iron-deficient rats fed diets containing ferrous sulphate or three different mixtures of cereals, seeds, and grains: homemade, light, and regular. Abbreviations: CG: control group; HMC: homemade cereals, seeds, and grains mixture; LMC: light cereals, seeds, and grains mixture; RMC: regular cereals, seeds, and grains mixture. Results are expressed as mean \pm SD ( $n=8$ for all groups). Mean values followed by different letters are significantly different $(P<0.05)$.

butyrate and acetate, no significant differences were observed between the control and test groups. As for caecal $\mathrm{pH}$, no difference was found between all groups (Table 6). Pearson's correlation revealed that acetate $(\mathrm{r}=0.7088, p=0.001)$ and propionate $(\mathrm{r}=0.5712, p=0.0018)$ concentrations were associated with fiber intake.

\section{Discussion}

The high energy density average of the three mixtures of cereals, seeds, and grains and their high levels of protein and lipids, are related to the presence of food sources such as oat, soy flour, wheat germ, sesame, and flaxseed in the mixtures tested. With regard to dietary fiber, LMC showed soluble dietary fiber 
Enes et al.

Table 5. Consumption of total fiber (g), insoluble fiber $(\mathrm{g})$, soluble fiber $(\mathrm{g})$, tannin $(\mathrm{mg})$, and phytate (mg).

\begin{tabular}{cccc}
\hline Variables & HMC & LMC & RMC \\
\hline Total Dietary Fiber (g) & $38.45 \pm 2.10^{\mathrm{c}}$ & $55,40 \pm 2.41^{\mathrm{a}}$ & $49.52 \pm 3.64^{\mathrm{b}}$ \\
Insoluble Dietary Fiber (g) & $32.07 \pm 1.76^{\mathrm{c}}$ & $33.97 \pm 1.53^{\mathrm{b}}$ & $36.33 \pm 2.67^{\mathrm{a}}$ \\
Soluble Dietary Fiber (g) & $6.37 \pm 0.35^{\mathrm{c}}$ & $21.15 \pm 0.92^{\mathrm{a}}$ & $13.18 \pm 0.97^{\mathrm{b}}$ \\
Phytate (mg) & $1.44 \pm 0.08^{\mathrm{a}}$ & $0.95 \pm 0.04^{\mathrm{b}}$ & $0.79 \pm 0.06^{\mathrm{c}}$ \\
Tannin (mg) & $651.87 \pm 35.77^{\mathrm{b}}$ & $473.25 \pm 20.66^{\mathrm{c}}$ & $3,038.42 \pm 223.67^{\mathrm{a}}$ \\
\hline
\end{tabular}

Results are expressed as mean \pm SD. HMC: Homemade mixture of cereals, seeds, and grains; LMC: Light mixture cereals, seeds, and grains; RMC: Regular mixture of cereals, seeds, and grains. For each evaluated characteristic, means followed by the same lowercase letter in the lines are not significantly different at $5 \%$ probability by Duncan test.

Table 6. Intestinal concentration of short chain fatty acids $(\mu \mathrm{mol} / \mathrm{g})$ and caecal $\mathrm{pH}$.

\begin{tabular}{ccccc}
\hline Variables & GC & HMC & LMC & RMC \\
\hline Acetate $(\mu \mathrm{mol} / \mathrm{g})$ & $17.38 \pm 2.56^{\mathrm{A}}$ & $16.38 \pm 2.17^{\mathrm{Aa}}$ & $20.18 \pm 5.48^{\mathrm{Aa}}$ & $14.93 \pm 2.56^{\mathrm{Ab}}$ \\
Propionate $(\mu \mathrm{mol} / \mathrm{g})$ & $53.07 \pm 6.13^{\mathrm{A}}$ & $67.9 \pm 2.81^{\mathrm{Ba}}$ & $65.49 \pm 11.08^{\mathrm{Ba}}$ & $55.21 \pm 7.80^{\mathrm{Aa}}$ \\
Butyrate $(\mu \mathrm{mol} / \mathrm{g})$ & $1.16 \pm 0.34^{\mathrm{A}}$ & $1.06 \pm 0.41^{\mathrm{Aa}}$ & $0.85 \pm 0.21^{\mathrm{Aa}}$ & $1.21 \pm 0.37^{\mathrm{Aa}}$ \\
Total SCFA $(\mu \mathrm{mol} / \mathrm{g})$ & $72.41 \pm 7.33^{\mathrm{A}}$ & $84.59 \pm 7.59^{\mathrm{Aa}}$ & $85.32 \pm 13.45^{\mathrm{Aa}}$ & $71.36 \pm 9.13^{\mathrm{Aa}}$ \\
Caecal $\mathrm{pH}$ & $7.00 \pm 0.00^{\mathrm{A}}$ & $7.10 \pm 0.20^{\mathrm{Aa}}$ & $7.10 \pm 0.30^{\mathrm{Aa}}$ & $7.10 \pm 0.20^{\mathrm{Aa}}$ \\
\hline
\end{tabular}

Results are expressed as mean \pm SD. CG: Control group; HMC: Homemade mixture of cereals, seeds, and grains; LMC: Light mixture cereals, seeds, and grains; RMC: Regular mixture of cereals, seeds, and grains. For each evaluated characteristic, means followed by the same capital letter in the lines are not significantly different at $5 \%$ probability by Dunnet's test. For each evaluated characteristic, means followed by the same lowercase letter in the lines are not significantly different at $5 \%$ probability by Duncan's test.

concentration two times higher than that of RMC and three fold higher than that of HMC. This difference may be associated to the presence of passion fruit peel flour, which contains high level of pectin, in the LMC formulation. The differences in phytate molar ratio can be related to some factors: food components of the mixture, the industry processing (in some cases), or homemade mixture. The LMC and RMC formulations are industrialized mixtures and, according to Siqueira et al. (2001), the grains are roasted during processing, which significantly reduces phytate content. During HMC preparation, the grains were not roasted, which may explain the higher phytate:iron molar ratio in HMC, even in the presence of higher iron content in LMC and RMC, which is due to the higher phytate content in HMC. The higher tannin content in the RMC mixture may be related to the presence of cocoa and guaraná, which are not present in the LMC mixture and are sources of polyphenols, especially flavanols (Carlson \& Thompson, 1998; Wollgast \& Anklam, 2000).

In the repletion period, there was an increase in $\mathrm{Hb}$ concentration and $\mathrm{Hb}-\mathrm{Fe}$ pool in all experimental groups. At the end of repletion period, LMC showed higher hemoglobin recovery, relative biological value, and iron bioavailability similar to those of the CG (ferrous sulfate). There was no difference in the parameters mentioned above in all experimental groups. Nevertheless, the presence of tannin may have reduced mineral bioavailability since there is an association between tannin intake and iron bioavailability $(\mathrm{r}=-0.4029 ; p=0.0255)$, according to the Pearson correlation. In this study, no association between total dietary fiber or its fractions and iron bioavailability was observed, which may strengthen the theory that dietary fiber does not impair iron absorption but other components that are coupled with it, as well as phenolic acids, flavanols, polyphenols, tannins, and others (Brune et al., 1989; Christian \& Seshadri, 1989). Weber et al. (2010) tested the effect of a dietary fiber mixture on iron absorption and did not find any influence of the dietary fiber content in rats recovering from anaemia. Martino et al., (2011), observed no effect of dietary fiber of hull soybean on iron bioavailability. However, other studies have pointed out that anemic animals fed soluble fiber showed recovery of hemoglobin similar to that of the control group; in those studies, ferrous sulfate was used as the control diet (De Cássia Freitas et al., 2006; Feltrin et al., 2009). The lack of consensus among various studies is due to experimental conditions such as short-term or long-term consumption of the food test, experimental models, the food matrix, and the age and/or nutritional/physiologic status of the animals (Lobo et al., 2007, 2011; Scholz-Ahrens \& Schrezenmeir, 2007).

The higher level of propionate in the caecal content, especially in the LMC group, is of great importance because this group had better iron bioavailability and higher soluble dietary fiber intake although there was no difference in the caecal $\mathrm{pH}$. Microbiota ferments non-digestible carbohydrates producing SCFA, lowering intestinal $\mathrm{pH}$ and improving the solubility of iron (Scholz-Ahrens \& Schrezenmeir, 2007). Weber et al. (2010) found significant reduction in the intestinal $\mathrm{pH}$ in animals fed a diet containing a mixture with high fiber content. Other authors found similar results, especially in diets supplemented with soluble dietary fiber (Scholz-Ahrens \& Schrezenmeir, 2002; Lobo et al., 2011).

These preliminary findings in an animal model must be confirmed in studies involving humans using appropriate methods for evaluation of iron bioavailability. These data also suggest that depending on the iron source, the digestion of nonheme iron into the common pool or its subsequent absorption can be influenced by the effects of the food matrix (Hallberg et al., 1986), and they show that the iron content of the mixtures studied were not the only factor responsible for mineral bioavailability. 


\section{Conclusions}

The light mixture of cereals, seeds, and grains showed higher iron bioavailability, possibly due to the lower tannin intake by the animals and a higher level of propionate in the fecal content associated with the intermediary contents of phytate and iron. Therefore, the results of this study showed that the light mixture of cereals, seeds, and grains used had no negative effect on iron homeostasis.

The authors declare that they have no conflict of interest in the research.

\section{Acknowledgments}

The authors are grateful for the financial support provided by the Fundação de Amparo à Pesquisa do Estado de Minas Gerais (FAPEMIG) (Research Project APQ 00421-11) and to the Coordenação de Aperfeiçoamento de Pessoal de Nível Superior (CAPES) for the fellowship granted to Bárbara Nery Enes, Natália Elizabeth Galdino Alves and Carlos Mário Martins Silveira. We also wish to thank Ceres Mattos Della Lucia and Gean Carla Pereira for reviewing the manuscript.

\section{References}

Association of Official Analytical Chemists - AOAC. (2002). Official Methods of Analysis of the AOAC International. Gaithersburg: AOAC.

Bekri, S., Gual, P., Anty, R., Luciani, N., Dahman, M., Ramesh, B., Iannelli, A., Staccini-Myx, A., Casanova, D., Ben Amor, I., SaintPaul, M. C., Huet, P. M., Sadoul, J. L., Gugenheim, J., Srai, S. K. S., Tran, A., \& Le Marchand-Brustel, Y. (2006). Increased Adipose Tissue Expression of Hepcidin in Severe Obesity Is Independent From Diabetes and NASH. Gastroenterology, 131(3), 788-796. http:// dx.doi.org/10.1053/j.gastro.2006.07.007

Brune, M., Rossander, L., \& Hallberg, L. (1989). Iron absorption and phenolic compounds: importance of different phenolic structures. European Journal of Clinical Nutrition, 43(8), 547-557.

Burns, R. E. (1971). Method for Estimation of Tannin in Grain Sorghum. Agronomy Journal, 63(3), 511-512. http://dx.doi. org/10.2134/agronj1971.00021962006300030050x

Callegaro, M. G. K., Diettrich, T., Alves, E., Milbradt, B. G., Denardin, C. C., Silva, L. P., \& Emanuelli, T. (2010). Supplementation with fiber-rich multimixtures yields a higher dietary concentration and apparent absorption of minerals in rats. Nutrition Research, 30(9), 615-625. http://dx.doi.org/10.1016/j.nutres.2010.08.005

Carlson, M., \& Thompson, R. (1998). Liquid Chromatographic Determination of Methylxanthines and Catechins in Herbal Preparations Containing Guarana. Journal of AOAC International, 81(4), 691-701.

Christian, P., \& Seshadri, S. (1989). Counteracting the inhibitory effect of tea on the in-vitro availability of iron from cereal meals. Journal of the Science of Food and Agriculture, 49(4), 431-436. http://dx.doi. org/10.1002/jsfa.2740490405

De Cássia Freitas, K., Amancio, O. M. S., Ferreira Novo, N., FagundesNeto, U., \& De Morais, M. B. (2006). Partially hydrolyzed guar gum increases intestinal absorption of iron in growing rats with iron deficiency anemia. Clinical Nutrition, 25(5), 851-858. http://dx.doi. org/10.1016/j.clnu.2006.02.010
Drabkin, D. L., \& Austin, J. H. () 1935. Spectrophotometric studies II. Preparations from washed blood cells: nitric oxide hemoglobin and sulphemoglobin. Journal of Biological Chemistry, 112, 51-65.

Feltrin, C., Batista de Morais, M., De Cássia Freitas, K., Beninga de Morais, T., Fagundes Neto, U., \& Silvério Amancio, O. (2009). Effect of Soluble Fiber Pectin on Growth and Intestinal Iron Absorption in Rats During Recovery from Iron Deficiency Anemia. Biological Trace Element Research, 129(1), 221-228. http://dx.doi.org/10.1007/ s12011-008-8307-4

Gomes, J. C. (1996). Análise de alimentos. Viçosa: Universidade Federal de Viçosa, Departamento de Tecnologia de Alimentos;. 126 p.

Hallberg, L., Brune, M., \& Rossander, L. (1986). Low bioavailability of carbonyl iron in man: studies on iron fortification of wheat flour. American Journal of Clinical Nutrition, 43(1), 59-67.

Latta, M., \& Eskin, M. (1980). A simple and rapid colorimetric method for phytate determination. Journal of Agricultural and Food Chemistry, 28(6), 1313-1315. http://dx.doi.org/10.1021/jf60232a049

Lobo, A. R., Cocato, M. L., Borelli, P., Gaievski, E. H. S., Crisma, A. R., Nakajima, K., Nakano, E. Y., \& Colli, C. (2011). Iron bioavailability from ferric pyrophosphate in rats fed with fructan-containing yacon (Smallanthus sonchifolius) flour. Food Chemistry, 126(3)., 885-891. http://dx.doi.org/10.1016/j.foodchem.2010.11.067

Lobo, A. R., Colli, C., Alvares, E. P., \& Filisetti, T. M. C. C. (2007). Effects of fructans-containing yacon (Smallanthus sonchifolius Poepp \& Endl.) flour on caecum mucosal morphometry, calcium and magnesium balance, and bone calcium retention in growing rats. British Journal of Nutrition, 97(04), 776-785. http://dx.doi. org/10.1017/S0007114507336805

Mahoney, A. W., Van Orden, C. C., \& Hendricks, D. C. (1974). Efficiency of concerting food iron into haemoglobin by the anaemic rats. Nutrition \& Metabolism, 17, 223-230. http://dx.doi. org/10.1159/000175540

Martino, H. S. D., Carvalho, A. W., Silva, C. O., Dantas, M. I. S., Natal, D. I. G., \& Costa, N. M. B. (2011). The use hull soybean flour of heattreated grains does not affect iron bioavailability in rats. Archivos Latinoamericanos de Nutricíon, 61(2), 135-142.

Maxson, E. D., \& Rooney, L. M. (1972). Evaluation of methods for tannin analysis in sorghum grain. Cereal Chemistry, 49, 719-729.

McClung, J. P., \& Karl, J. P. (2009). Iron deficiency and obesity: the contribution of inflammation and diminished iron absorption. Nutrition Reviews, 67(2), 100-104. http://dx.doi.org/10.1111/j.17534887.2008.00145.x

Mello, V. D. D., \& Laaksonen, D. E. (2009). Fibras na dieta: tendências atuais e benefícios à saúde na síndrome metabólica e no diabetes melito tipo 2. Arquivos Brasileiros de Endocrinologia \& Metabologia, 53, 509-518. http://dx.doi.org/10.1590/S0004-27302009000500004

Neymotin, F., \& Sen, U. (2011). Iron and Obesity in Females in the United States. Obesity, 19(1), 191-199. http://dx.doi.org/10.1038/ oby.2010.112

Price, M. L., Van Scoyoc, S., \& Butler, L. G. (1978). A critical evaluation of the vanillin reaction as an assay for tannin in sorghum grain. Journal of Agricultural and Food Chemistry, 26(5), 1214-1218. http:// dx.doi.org/10.1021/jf60219a031

Reeves, P. G., Forrest, H. N., \& Fahey Junior, G. C. (1993). AIN-93 purified diets for laboratory rodents: final report of the American Institute of Nutrition ad hoc writing committee on the reformulation of the AIN-76A rodent diet. Journal of Nutrition, 123(11), 1939-51.

Siqueira, S. F. A., Egle, M. A., Sousa, L. M., \& Souza, E. M. (2001). Phytate from an alternative dietary supplement has no effect on 
the calcium, iron and zinc status in undernourished rats. Archivos Latinoamericanos de Nutrición, 51(3), 250-257.

Schlemmer, U., Frølich, W., Prieto, R. M., \& Grases, F. (2009). Phytate in foods and significance for humans: Food sources, intake, processing, bioavailability, protective role and analysis. Molecular Nutrition \& Food Research, 53(S2), S330-S375. http://dx.doi.org/10.1002/ mnfr.200900099

Scholz-Ahrens, K. E., \& Schrezenmeir, J. R. (2002). Inulin, oligofructose and mineral metabolism - experimental data and mechanism. British Journal of Nutrition, 87(2), 179-186. http://dx.doi. org/10.1079/BJN/2002535

Scholz-Ahrens, K. E., \& Schrezenmeir, J. R. (2007). Inulin and Oligofructose and Mineral Metabolism: The Evidence from Animal Trials. Journal of Nutrition, 137(11), 2513S-2523S.

Shah, M., Chandalia, M., Adams-Huet, B., Brinkley, L. J., Sakhaee, K., Grundy, S. M., \& Garb, A. (2009). Effect of a High-Fiber Diet Compared With a Moderate-Fiber Diet on Calcium and Other Mineral Balances in Subjects With Type 2 Diabetes. Diabetes Care, 32,899-995. http://dx.doi.org/10.2337/dc09-0126

Slavin, J. L. (2005). Dietary fiber and body weight. Nutrition, 21(3), 411-418. http://dx.doi.org/10.1016/j.nut.2004.08.018

Smiricky-Tjardes, M. R., Grieshop, C. M., Flickinger, E. A., Bauer, L. L., \& Fahey Junior, G. C. (2003). Dietary galactooligosaccharides affect ileal and total-tract nutrient digestibility, ileal and fecal bacterial concentrations, and ileal fermentative characteristics of growing pigs. Journal of Animal Science, 81(10), 2535-2545.
Towo, E., Matuschek, E., \& Svanberg, U. (2006). Fermentation and enzyme treatment of tannin sorghum gruels: effects on phenolic compounds, phytate and in vitro accessible iron. Food Chemistry, 94(3), 369-376. http://dx.doi.org/10.1016/j.foodchem.2004.11.027

Verma, A. K., \& Banerjee, R. (2010). Dietary fibre as functional ingredient in meat products: a novel approach for healthy living - a review Journal of Food Science and Technology, 47, 247-257.

Weber, T. K., Freitas, K. D. C., Amancio, O. M. S., \& De Morais, M. B. (2010). Effect of dietary fibre mixture on growth and intestinal iron absorption in rats recovering from iron-deficiency anaemia. British Journal of Nutrition, 104(10), 1471-1476. http://dx.doi.org/10.1017/ S0007114510002497

Wollgast, J., \& Anklam, E. (2000). Review on polyphenols in Theobroma cacao: changes in composition during the manufacture of chocolate and methodology for identification and quantification. Food Research International, 33(6), 423-447. http://dx.doi.org/10.1016/ S0963-9969(00)00068-5

World Health Organization. (2011). Overweight and obesity. Fact sheet n. 311. Geneva: WHO.

Zago, M. A., Falcão, R. P., \& Pasquini, R. (2005). Hematologia: fundamentos e práticas. São Paulo: Ed. Atheneu.

Zimmermann, M. B., \& Hurrell, R. F. (2007). Nutritional iron deficiency. The Lancet, 370(9586), 511-520. http://dx.doi.org/10.1016/S01406736(07)61235-5 